\title{
Serum protein response and renal failure in canine Babesia annae infection
}

\author{
Angel Tomas CAMACHO ${ }^{\mathrm{a} *}$, Francisco Javier GUITIAN ${ }^{\mathrm{b}}$, Estrella PALLAS ${ }^{\mathrm{c}}$, \\ Juan Jesus GeSTAL ${ }^{\mathrm{d}}$, Sonia OLMEDA ${ }^{\mathrm{e}}$, Heidi GOETHERT ${ }^{\mathrm{f}, \mathrm{g}}$, \\ Sam TELFORD III ${ }^{\mathrm{f}, \mathrm{g}}$, Andrew SPIELMAN ${ }^{\mathrm{f}}$ \\ ${ }^{a}$ Laboratorio Lema \& Bandín, C./Lepanto 5, bajo, 36201 Vigo, Spain \\ $\mathrm{b}$ The Royal Veterinary College, Hawkshead Lane, North Mymms, Hatfield AL9 7TA, United Kingdom \\ c Servicio de Otorrinolaringología, Hospital Xeral-Cíes, C./ Pizarro, 36203 Vigo, Spain \\ d Departamento de Medicina Preventiva y Salud Pública, Hospital Clínico Universitario, A. Choupana, \\ 15706 Santiago de Compostela, Spain \\ e Departamento de Patología Animal I, Facultad de Veterinaria, Universidad Complutense, \\ Avda. Puerta de Hierro s/n, 28040 Madrid, Spain \\ ${ }^{\mathrm{f}}$ Laboratory of Public Health Entomology, Department of Immunology and Infectious Diseases, \\ Harvard School of Public Health, 665 Huntington Avenue, Boston, Massachusetts 02115, USA \\ $\mathrm{g}$ Present address: Division of Infectious Diseases, Tufts University School of Veterinary Medicine, \\ 200 Westboro Road, North Grafton, Massachusetts 01536, USA
}

(Received 29 June 2004; accepted 11 February 2005)

\begin{abstract}
Babesia annae piroplasms have recently been recognised as a cause of infection and disease among dogs in Europe. The pathogenesis and clinical implications of this emerging disease remain poorly understood. We conducted this study to describe the electrophoretic profiles associated with the infection and to determine if $B$. annae associated azotaemia is caused by renal failure. We examined by microscopy 2979 canine blood samples submitted to a diagnostic laboratory in NW Spain between September 2001 and April 2002. Small ring-shaped piroplasms were detected in blood smears of 87 samples and the identity of 58 of these presumptive cases were confirmed by PCR. This group of 58 infected dogs and a reference group of 15 healthy non-infected dogs were our study population. For all the dogs, serum protein response to -albumin, alpha-1 globulin, alpha-2 globulin, beta globulin and gamma globulin- was measured by capillary electrophoresis. The response of infected and non-infected dogs was compared and within infected dogs, the response of those with azotaemia (19) was compared with that of non-azotaemic dogs (39). Infected dogs presented a significant elevation of total proteins and all the different globulin fractions, and significantly lower levels of albumin compared to non-infected dogs. Among infected dogs, those presenting azotaemia had significantly lower concentrations of total proteins, albumin, beta and gamma globulins, and significantly higher values of alpha- 2 globulin. Specific gravity was below the threshold of 1025 for all dogs with azotaemia for which a urine sample was available (7) suggesting that azotaemia, in these dogs was of renal origin. Azotaemic dogs had higher concentrations of cholesterol and triglycerides, probably as a result of a liver compensatory response to the loss of proteins. We conclude that serum protein response in B. annae infected dogs corresponds to the pattern of a haemolytic syndrome with intense inflammatory reaction and that the azotaemia associated to the infection is very likely of renal origin.
\end{abstract}

serum proteins / Babesia annae / azotaemia / renal failure

* Corresponding author: atcamacho@teleline.es 


\section{INTRODUCTION}

Babesiosis is a parasitic disease of domestic and wild mammals caused by tickborne hematozoan organisms (piroplasms) of the genus Babesia [11, 20]. Canine piroplasms have historically been classified as "large babesia" (Babesia canis) and "small babesia" (Babesia gibsoni) based on the size of their intraerythrocytic forms. Phylogenetic analysis of DNA sequences derived from the polymerase chain reaction (PCR) amplification of ribosomal genes has allowed further subvidision [10] of these taxa. Small Babesia now include two strains of Babesia gibsoni: "Asia" and "California", and a recently identified small Babesia $[3,4,23]$, which is more closely related to Babesiamicroti than to Babesia gibsoni and has been tentatively referred to as Babesia annae [6]. This newly recognised piroplasm appears to be endemic in NW Spain [3].

The disease caused by Babesia spp. infections typically comprises a syndrome characterised by hyperthermia, anaemia and haemoglobinuria [2, 7], although in many hosts subclinical or mild infection is common. Similarly to other "small" babesia, in dogs, B. annae infection causes severe illness. Intense regenerative anaemia, thrombocytopenia and azotaemia are common findings among infected dogs and we have estimated [5] the case fatality rate during the first week following diagnosis to be $22 \%$. In that study, a great proportion of dogs infected by B. annae developed serum biochemistry abnormalities compatible with renal disease. However, we could not establish an association between infection and renal failure because the diagnosis of renal failure was not corroborated by means such as post-mortem examination and histopathology or urine analysis. Thus, the question of whether $B$. annae infection is a cause of renal failure remains unanswered.

Serum protein separation has been increasingly used as an aid in the diagnosis of canine diseases. The separation and identification of different protein fractions facilitates the understanding of the pathological changes associated with different conditions [1]. Even for the more common forms of canine babesiosis, the alterations in serum protein levels and the electrophoretic pattern following natural infection have been poorly studied. Among the three studies documenting changes in the serum protein levels in naturally occurring Babesia canis infections, a decrease in serum albumin concentration is a consistent finding $[13,15]^{1}$. In relation to the levels of the different globulin fractions, one study did not quantify them [15], another showed a significant decrease in alpha-2 globulin and increased gamma globulins ${ }^{1}$, and the third one reported differences in the levels of alpha globulins according to the severity of the disease [13].

Information is even more rudimentary for the recently recognised $B$. annae infection, whose pathogenesis and clinical implications are still poorly understood. On our first report of a series of cases [3], which followed the first case report of the infection by Zahler et al. [23], we obtained mean serum values of total protein and albumin which were within commonly accepted normal reference ranges but we did not study the electrophoretic profile associated to the infection. Furthermore, no reference group of noninfected dogs was included for comparison.

The present study had two objectives: first, to describe the electrophoretic profiles associated with $B$. annae infection and to assess differences in this profile between infected and healthy non-infected dogs. Secondly, to determine if $B$. annae associated azotaemia is of pre-renal origin or caused by renal failure.

\section{MATERIALS AND METHODS}

\subsection{Study design and study animals}

During the year 2002, 2979 dogs had blood samples submitted for haematological

\footnotetext{
${ }^{1}$ Malherbe W.D., A clinico-pathological study of Babesia canis infection in dogs, Ph.D. thesis, University of Pretoria, 1966.
} 
analysis to a diagnostic laboratory located in Vigo (NW Spain). All the samples were analysed by brightfield microscopy of Giemsa stained thin blood smears. Small ring-shaped piroplasms that are distinguishable from B. canis or B. gibsoni (and herein designated $B$. annae), were detected in 87 of them. The criteria for identifying $B$. annae as opposed to $B$. canis or B. gibsoni included the extremely small size of the parasite, and the absence of large paired pyriforms or small tetrads. Dogs for which a serum sample was not available (22) were excluded from the case series, and PCR was used to confirm the identity of the remaining 65 cases. We confirmed the identity of 58 cases by PCR using the Bab 1/Bab4 primer set, which is specific for $B$. microtilike parasites [17] and will amplify $B$. annae but not B. gibsoni or B. canis. It was decided to exclude from further analysis the 7 cases detected by microscopy and not confirmed by PCR. This subset of 58 dogs constituted the study population and partially overlapped with the case series that we have recently described [5], which consisted of all the dogs that had blood samples submitted to the same laboratory between September 2001 and April 2002 and were diagnosed by microscopy as infected by $B$. microti-like piroplasms. Eighteen dogs included in the previous case series were also included in the one we are now presenting.

For all the dogs in the study population, serum concentrations of urea, creatinine, ALT, AST, triglycerides, cholesterol and proteins were measured at the time infection was diagnosed. The dogs were classified as presenting azotaemia or not according to urea and creatinine values (see below).

Urine density was determined for the subgroup of dogs for which a urine sample was submitted by the veterinarian in addition to the blood and serum samples $(n=$ 15).

A reference population of 15 healthy dogs was selected among the group of
2892 non-infected dogs. Reference dogs were the last 15 dogs from which samples were received in the laboratory during the study period and fulfilled the following criteria: (1) they were classified as healthy by the veterinarian submitting the sample, (2) they had haematological analysis (including an examination of blood smear) done and were classified as noninfected, (3) a serum sample was available.

\subsection{Laboratory methods}

Haematological (complete blood count) count was carried out with a Coulter STKS2 VCS automatic counter (Coulter Corporation, Miami, FL, USA ). Brilliant cresyl blue and Giemsa-stained peripheral blood smears were performed as described by Nelson and Morris [16]. An animal was considered infected and a candidate for the study when single intraerythrocytic, ringshaped piroplasms were microscopically observed $(1000 \times)$ in Giemsa-stained blood smears. All blood smears were read by the primary author.

For PCR analysis, DNA was extracted from $5 \mathrm{~mm}$ blood spots dried onto Whatman paper strips using a standard phenol-chloroform method. DNA was resuspended in $50 \mu \mathrm{L}$ water. The Bab1/Bab4 primer set was used to confirm the identity of the piroplasms.

Serum concentrations of urea, creatinine, ALT, AST, triglycerides, cholesterol and proteins were determined with a clinical chemistry analyser (CL-7200, Shimadzu, Shimadzu Corporation, Kyoto, Japan). A dog was classified as presenting azotaemia when the levels of urea were $>55 \mathrm{mg} / \mathrm{dL}$ and levels of creatinine $>1.6 \mathrm{mg} / \mathrm{dL}$.

Serum protein electrophoresis of albumin, alpha-1 globulin, alpha-2 globulin, beta globulin and gamma globulin was carried out with a Paragon CZE 2000 capillary electrophoresis system (Beckman Coulter, Inc, Fullerton, CA, USA) [9, 21].

Urine was analysed with a refractometer Atago SUR-NE (Atago Co. Ltd., Tokyo, 
Japan) for measurement of urine density within a range of 1000-1060.

Haematology and serum biochemistry analyses were done in Laboratorio Lema \& Bandin (Vigo, Spain). The DNA amplification analysis was done at Harvard School of Public Health (USA).

\subsection{Data analysis}

Descriptive statistics were computed for all the variables representing haematolotical and serum biochemistry parameters (Tab. I). For each variable, the presence of outliers and the assumption of normality were graphically and numerically assessed.

The hypothesis that median levels of total protein, albumin and the different globulin fractions were different for the three groups of dogs (non-infected, infected without azotaemia and infected with azotaemia) was assessed by means of a Kruskal-Wallis test of association. For those variables for which a significant overall difference was found across groups, the pairs of groups were compared using the Mann-Whitney test of association.

For all the remaining haematological and serum biochemistry parameters and for urine density, the hypothesis that the median values were different between infected dogs with and without azotaemia was assessed by means of the Mann-Whitney test of association. For infected dogs with azotaemia $(n=19)$, all pairwise correlations between these parameters were graphically and numerically explored. Scatter plots were examined and Pearson $r$ (for linear relationships) or Spearman rho (for relationships suspected not to be linear) were calculated.

Logistic regression was used to estimate the relationship between all the different parameters measured in infected dogs and the odds of an infected dog presenting azotaemia. Our model-building strategy involved two steps [8]. In the first step, all single variables were screened in a simple logistic regression. Only variables significant at
$P<0.25$ were included in the second step of the analysis. Before continuing with the second step of the analysis, all the selected variables were checked for inter-correlation, and in case of a pair of variables whether there was a significant association $(P<0.05)$ and both with $P<0.25$, the variable judged as most biologically plausible was used as a candidate in the multivariable analysis. Finally, the selection of the most parsimonious multivariable logistic model was achieved by backward stepwise elimination of non-significant $(P>0.1$, twotailed tests) factors.

Associations were deemed significant if $P<0.05$ (two-tailed), (SPSS 11.5, SPSS Inc. Chicago, IL, USA ).

Data analysis was done in The Royal Veterinary College, United Kingdom.

\section{RESULTS}

Among infected dogs $(n=58)$ serum creatinine concentrations ranged between 0.4 and $11 \mathrm{mg} / \mathrm{dL}$ (median $=1.05$; Interquartile range: 0.8-4.05). Urea values ranged between 19 and $558 \mathrm{mg} / \mathrm{dL}$ (median $=38$; Interquartile range: $30.5-309.25)$. Nineteen of the infected dogs (32.8\%) had creatinine concentrations higher than $1.6 \mathrm{mg} / \mathrm{dL}$. All of these dogs had urea values above $200 \mathrm{mg} / \mathrm{dL}$.

Descriptive statistics for all the remaining studied variables, as well as the results of the tests of association are presented in Table I.

For all the variables representing serum protein levels, significant (Kruskal Wallis, $P \leq 0.001$ ) differences were found between the three groups and the differences between the pairs of groups were assessed. The distribution of the serum concentrations of total proteins, albumin, and the different globulin fractions for infected and noninfected dogs and for infected dogs with and without azotaemia are presented in Figures 1 and 2 respectively. 
Table I. Descriptive statistics for the different studied variables, and the results of the tests of association. Data from 58 dogs infected with Babesia annae and 15 non-infected healthy dogs.

\begin{tabular}{|c|c|c|c|c|}
\hline Variable (units) & Group (number of dogs) & Median & Interquartile range & $P^{*}$ \\
\hline \multirow{2}{*}{$\begin{array}{l}\text { Leukocyte count } \\
\left(10^{3} \text { cells } / \mathrm{mL}\right)\end{array}$} & Infected without azotaemia (39) & 13.0 & $9.7-18.5$ & \multirow[t]{2}{*}{0.960} \\
\hline & Infected with azotaemia (19) & 11.9 & $10.8-15.0$ & \\
\hline \multirow{2}{*}{$\begin{array}{l}\text { Red blood cell count } \\
\left(10^{6} \text { cells } / \mathrm{mL}\right)\end{array}$} & Infected without azotaemia (39) & 2.57 & $1.80-3.69$ & \multirow[t]{2}{*}{0.271} \\
\hline & Infected with azotaemia (19) & 2.05 & $1.40-3.67$ & \\
\hline \multirow[t]{2}{*}{ Haemoglobin $(\mathrm{g} / \mathrm{dL})$} & Infected without azotaemia (39) & 6.4 & $4.8-9.1$ & \multirow[t]{2}{*}{0.156} \\
\hline & Infected with azotaemia (19) & 5.6 & $3.2-9.1$ & \\
\hline \multirow[t]{2}{*}{ Hematocrit (\%) } & Infected without azotaemia (39) & 19.6 & $14.2-27.0$ & \multirow[t]{2}{*}{0.211} \\
\hline & Infected with azotaemia (19) & 16.9 & $10.3-27.0$ & \\
\hline \multirow{2}{*}{$\begin{array}{l}\text { Platelet count } \\
\left(10^{3} \text { cells } / \mathrm{mL}\right)\end{array}$} & Infected without azotaemia (39) & 18 & $7-72$ & \multirow[t]{2}{*}{0.974} \\
\hline & Infected with azotaemia (19) & 23 & $8-46$ & \\
\hline \multirow{2}{*}{$\begin{array}{l}\text { Red cell distribution } \\
\text { width }(\%)\end{array}$} & Infected without azotaemia (39) & 16.8 & $14.3-19.1$ & \multirow[t]{2}{*}{0.393} \\
\hline & Infected with azotaemia (19) & 17.2 & $15.3-19.1$ & \\
\hline \multirow[t]{2}{*}{ Cholesterol (mg/dL) } & Infected without azotaemia $(39)^{\mathrm{b}}$ & 217 & $178-232$ & \multirow[t]{2}{*}{$<0.001$} \\
\hline & Infected with azotaemia $(19)^{\mathrm{c}}$ & 330 & $252-378$ & \\
\hline \multirow[t]{2}{*}{ Triglycerides (mg/dL) } & Infected without azotaemia $(39)^{\mathrm{b}}$ & 63 & $33-87$ & \multirow[t]{2}{*}{$<0.001$} \\
\hline & Infected with azotaemia $(19)^{\mathrm{c}}$ & 140 & $94-180$ & \\
\hline \multirow[t]{2}{*}{ AST (U/L) } & Infected without azotaemia $(39)^{\mathrm{b}}$ & 32 & $27-52$ & \multirow[t]{2}{*}{0.024} \\
\hline & Infected with azotaemia $(19)^{\mathrm{c}}$ & 47 & $41-68$ & \\
\hline \multirow[t]{2}{*}{$\operatorname{ALT}(\mathrm{U} / \mathrm{L})$} & Infected without azotaemia $(39)^{\mathrm{b}}$ & 31 & $23-63$ & \multirow[t]{2}{*}{0.025} \\
\hline & Infected with azotaemia $(19)^{\mathrm{c}}$ & 52 & $34-74$ & \\
\hline \multirow[t]{3}{*}{ Total protein $(\mathrm{g} / \mathrm{dL})$} & Reference $(15)^{b}$ & 6.0 & $5.8-6.2$ & \multirow[t]{3}{*}{$<0.001$} \\
\hline & Infected without azotaemia $(39)^{\mathrm{a}, \mathrm{c}}$ & 7.9 & $7.3-8.2$ & \\
\hline & Infected with azotaemia (19) b & 5.6 & $5.1-7.2$ & \\
\hline \multirow[t]{3}{*}{ Albumin (g/dL) } & Reference $(15)^{b, c}$ & 3.0 & $2.9-3.1$ & \multirow[t]{3}{*}{$<0.001$} \\
\hline & Infected without azotaemia (39) $)^{\mathrm{a}, \mathrm{c}}$ & 2.8 & $2.4-2.9$ & \\
\hline & Infected with azotaemia (19) ${ }^{\mathrm{a}, \mathrm{b}}$ & 2.0 & $2.0-2.3$ & \\
\hline \multirow[t]{3}{*}{ Alpha-1 (g/dL) } & Reference $(15)^{\mathrm{b}, \mathrm{c}}$ & 0.4 & $0.32-0.44$ & \multirow[t]{3}{*}{$<0.001$} \\
\hline & Infected without azotaemia (39) ${ }^{\mathrm{a}}$ & 0.68 & $0.51-0.79$ & \\
\hline & Infected with azotaemia (19) ${ }^{\mathrm{a}}$ & 0.51 & $0.39-0.79$ & \\
\hline Alpha-2 (g/dL) & Reference $(15)^{b, c}$ & 0.51 & $0.44-0.61$ & $<0.001$ \\
\hline & Infected without azotaemia (39) $)^{\mathrm{a}, \mathrm{c}}$ & 0.66 & $0.54-0.80$ & \\
\hline & Infected with azotaemia $(19)^{a, b}$ & 0.83 & $0.76-0.92$ & \\
\hline Beta $(\mathrm{g} / \mathrm{dL})$ & Reference $(15)^{\mathrm{b}}$ & 1.12 & $0.93-1.44$ & $<0.001$ \\
\hline & Infected without azotaemia $(39)^{\mathrm{a}, \mathrm{c}}$ & 2.31 & $1.70-2.70$ & \\
\hline & Infected with azotaemia $(19)^{\mathrm{b}}$ & 1.1 & $1.0-1.46$ & \\
\hline Gamma (g/dL) & Reference $(15)^{\mathrm{b}}$ & 1.02 & $0.92-1.10$ & 0.001 \\
\hline & Infected without azotaemia $(39)^{\mathrm{a}, \mathrm{c}}$ & 1.73 & $1.30-1.95$ & \\
\hline & Infected with azotaemia $(19)^{\mathrm{b}}$ & 0.91 & $0.69-1.73$ & \\
\hline Urine density $(\mathrm{g} / \mathrm{mL})$ & Infected without azotaemia $(8)^{\mathrm{c}}$ & 1.029 & $1.015-1.042$ & 0.019 \\
\hline & Infected with azotaemia $(7)^{b}$ & 1.010 & $1.005-1.016$ & \\
\hline
\end{tabular}

${ }^{a}$ Significantly different from the reference group (Mann-Whitney, $P<0.05$ ).

b Significantly different from the group "infected without azotaemia" (Mann-Whitney, $P<0.05$ ).

c Significantly different from the group "infected with azotaemia" (Mann-Whitney, $P<0.05$ ).

* By Kruskal-Wallis. 

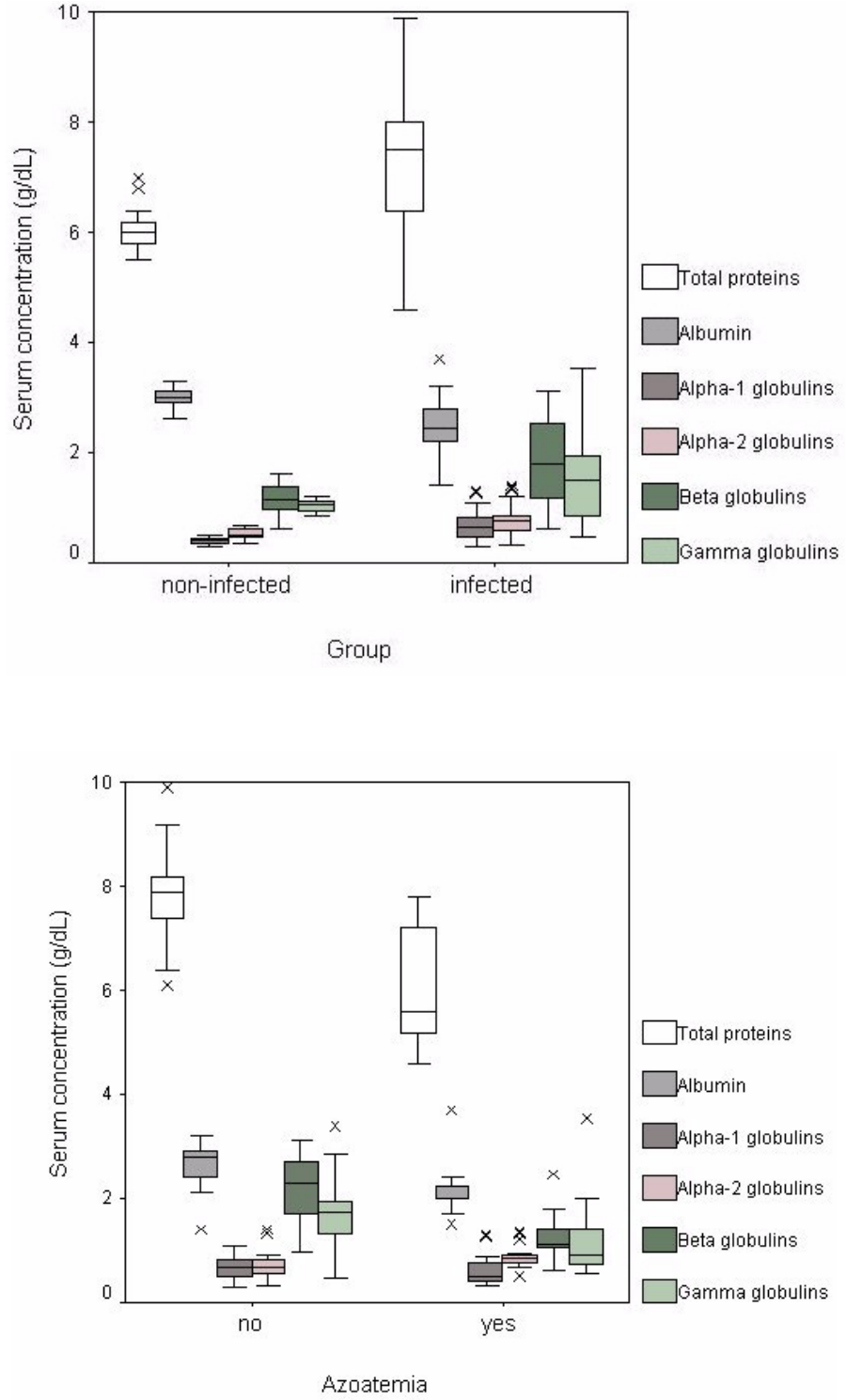

Figure 1. Box plots showing the median, interquartile range and outlying values (values more than $3 \times$ interquartile range from the upper or lower edge of the box) for total protein, albumin and different globulin fraction concentrations in 58 dogs infected with Babesia annae and 15 non-infected healthy dogs.
Figure 2. Box plots showing the median, interquartile range and outlying values (values more than $3 \times$ interquartile range from the upper or lower edge of the box) for total protein, albumin and different globulin fraction concentrations in 19 azotemic and 39 non-azotemic dogs infected with Babesia annae.
Infected dogs without azotaemia presented with a significant elevation of total proteins and all the different globulin fractions, and significantly lower levels of albumin compared to non-infected dogs. Infected dogs with azotaemia presented a significant elevation of alpha-1 and alpha-2 globulins and significantly lower albumin levels than non-infected dogs. Among infected dogs, those presenting azotaemia had significantly lower concentrations of total proteins, albumin, beta and gamma globulins, and significantly higher values of alpha-2 globulin. 
Infected dogs with and without azotaemia also differed significantly in their serum concentrations of cholesterol, triglycerides, AST and ALT and in their urine density. In infected dogs, the presence of azotaemia was associated with increased concentrations of cholesterol, triglycerides, ALT and AST and with decreased urine density.

Among the infected dogs with azotaemia, several bivariate correlations were detected as statistically significant. Serum concentrations of urea and creatinine were positively correlated as well as concentrations of AST - ALT and cholesterol - triglycerides. Higher albumin concentrations were significantly correlated with higher cholesterol and triglyceride concentrations and lower urine density.

Due to inter-correlation between the parameters of interest, only four variables were made available to the logistic regression model: red blood cell count, beta globulin, gamma globulin and ALT. Amongst these variables, only beta globulin and gamma globulin were retained in the final model. Higher values of beta globulin and gamma globulin were significantly $(P=0.001$ and $P=0.034$, respectively) associated with a decreased odds of an infected dog presenting azotaemia.

\section{DISCUSSION}

Our results indicate that the canine serum protein pattern is significantly altered by Babesia annae infection, with the nature and magnitude of these changes being different for infected dogs with or without biochemistry abnormalities compatible with renal disease. Non-azotaemic infected dogs showed a significant increase in total serum protein concentration, with globulins being responsible for this elevation.

Alpha-1 globulins are elevated in both groups of infected dogs with respect to the reference group. The most likely reason for this elevation is the release of acute phase reactants, such as alpha-1 antitrypsin (AT) and alpha 1-acid glycoprotein (AGP) in response to the inflammation process. The former reactant is an inhibitory protease produced in response to the liberation of collagenase by leukocytes. The biological role of the latter is still unknown.

Similarly, alpha-2 globulins are elevated in both groups of infected dogs with respect to the reference group, also most likely as a result of the release of acute phase reactants. Within infected dogs, those presenting azotaemia have higher concentrations of alpha- 2 globulins. This may represent an elevation of the levels of alpha- 2 macroglobulin as a mechanism to compensate for hypoalbuminemia. Marked elevations have been described in the nephrotic syndrome, as a mechanism to maintain oncotic pressure [18].

Infection is also associated with an increase in the concentration of beta-globulins, which might correspond to the presence of free-haemoglobin as a result of intense haemolytic anaemia. The observed band would likely be the result of haemoglobin-haptoglobin binding. The increase was only significant for dogs without azotaemia. A lack of elevation of beta globulin levels in infected dogs with azotaemia in contrast to infected dogs without azotaemia might be due to the following: (i) the deposit of immune complexes and the subsequent consumption and removal of $\mathrm{C} 3$ and $\mathrm{C} 4$ proteins from the serum [22]; (ii) the loss of transferrin through the kidney, which has been described in cases of renal disease [14]; or (iii) the fact that transferrin is a negative acute phase reactant, with levels decreasing during acute inflammatory processes which may be more likely in dogs with azotaemia.

Reference dogs and infected dogs with azotaemia presented similar concentrations of gamma globulin. Gamma globulin levels were significantly higher in infected dogs without azotaemia compared to the other two groups of dogs. Increased gamma globulin levels in this group of dogs might be the 
result of increased C-reactive protein, a highly sensitive acute phase reactant. The lack of a significant elevation of gamma globulin concentration in dogs with azotaemia might be caused by its urinary loss.

The magnitude of the decrease in albumin concentration in infected dogs was associated with the presence of azotaemia: serum albumin concentration was significantly lower for infected dogs with azotaemia than for infected dogs without azotaemia. The most likely explanation for this finding would be urinary loss of albumin associated with renal failure.

Urine samples were available for 15 of the 58 infected dogs (26\%) and in only 4 cases, specific gravity was above the accepted threshold of 1.025 . Specific gravity was below this limit for all dogs with azotaemia, and significantly differed between this group of dogs and infected dogs with azotaemia (Median 1.010 and 1.029, respectively; $P=0.02$ ). The observed association strongly suggests that azotaemia in these dogs was of renal origin. The nature of the study population (subset of a case series) did not allow us to directly extrapolate our results to the general population of $B$. annae infected dogs. Cases diagnosed at the laboratory were not necessarily fully representative of the population of infected dogs. However, we consider that the association between the presence of azotaemia and urine specific gravity was very unlikely the result of selection or confounding bias and that, consequently, it strongly supports the renal origin of the observed azotaemia. Furthermore, the differences observed in serum concentrations of albumin and globulin fractions between the different groups of dogs were all consistent with an impaired renal function in dogs with azotaemia. This finding differed notably from that observed in dogs infected with other Babesia species. Lobetti and Jacobson [12] studied 30 dogs infected with $B$. canis and reported that all had well concentrated urine.

As expected, significant positive bivariate correlations were found between urea and creatinine, cholesterol and triglycerides and ALT and AST concentrations.

Significant bivariate correlations were also found between albumin and cholesterol (positive), albumin and triglycerides (positive) and albumin and urine density (negative).

Although care should be taken when interpreting the negative correlation between urine density and albumin due to the low number of observations (7), we consider this an interesting finding which points to tubular injury as the main component of the renal damage, in at least some of the infected dogs with azotaemia. B. annae infection has been associated with a severe haemolytic anaemia [3]. The resulting haemoglobinuria could produce a tubulopathy, which will compromise the ability to concentrate urine. These dogs will tend to exhibit lower urine densities and higher albumin concentrations than dogs in which glomerular damage prevails. Glomerulonephritis has been described in association with Babesia infection [19] and could be the predominant component among dogs with lower levels of albumin and higher urine density.

Cholesterol and triglycerides concentration are significantly higher for infected dogs with azotaemia than for infected dogs without azotaemia. This finding also supported the renal origin of the azotaemia since it is very likely the result of the liver compensatory reaction to the loss of proteins: an increased production of proteins, including the lipid transport proteins in the alpha 2 (very low density-lipoproteins: VLDL) and beta (low density-lipoproteins: LDL) fractions. When the subgroup of azotemic infected dogs was studied, cholesterol and triglyceride concentrations were less elevated among dogs with more severe hypoalbuminemia (significant positive correlations between albumin and cholesterol and between albumin and triglycerides). We do not have a clear explanation for this observation, but differences in the stage or severity of the condition among these dogs, 
which might influence albumin loss and liver function could be responsible.

We conclude that the serum protein response in Babesia annae infected dogs corresponds with the pattern of a haemolytic syndrome with intense inflammatory reaction. The pattern differs significantly depending on the presence or absence of azotaemia, with azotaemic dogs presenting a more marked decrease in total protein and albumin levels and lower increases in beta and gamma-globulin concentrations. If the proportion of infected dogs presenting azotaemia which was detected in our lab $(36 \%$ for the previous case series; $33 \%$ in the present study) is a reasonable estimate of the true proportion of infected dogs that develop azotaemia, $B$. annae infection should be considered as a major cause of renal failure in endemic areas. Two mechanisms may be suggested as possible explanations for the observed renal damage: first, intense haemolytic anaemia, which is a potential cause of tubular injury, interstitial nephritis and glomerulopathy. Second, an autoimmune mechanism resulting in the deposit of immune complexes in the glomerulus and subsequent glomerulonephritis [19]. However, further studies are needed to precisely define the physiopathology of the infection and to assess the role of these mechanisms during its course.

\section{REFERENCES}

[1] Abate O., Zanatta R., Malisano T., Dotta U., Canine serum protein patterns using high-resolution electrophoresis (HRE), Vet. J. 159 (2000) 154-160.

[2] Abdullahi S.U., Mohammed A.A., Trimnell A.R., Clinical and haematological findings in 70 naturally occurring cases of canine Babesiosis, J. Small Anim. Pract. 31 (1990) 145147.

[3] Camacho A.T., Pallas E., Gestal J.J., Guitian F.J., Olmeda A.S., Goethert H.K., Telford S.R., Infection of dogs in north-west Spain with a Babesia microti-like agent, Vet. Rec. 149 (2001) 552-555.
[4] Camacho A.T., Pallas E., Gestal J.J., Guitian F.J., Olmeda A.S., Natural infection by a Babesia microti-like piroplasm in a splenectomised dog, Vet. Rec. 150 (2002) 381-382.

[5] Camacho A.T., Guitián F.J., Pallas E., Gestal J.J., Olmeda A.S., Goethert H.K., Telford S.R., Spielman A., Azotemia and mortality among Theileria annae infected dogs, J. Vet. Intern. Med. 18 (2004) 141-146.

[6] Goethert H.K., Telford S.R., What is Babesia microti? Parasitology 127 (2003) 301-309.

[7] Irwin P.J., Hutchinson G.W., Clinical and pathological findings of Babesia infection in dogs, Aust. Vet. J. 68 (1991) 204-209.

[8] Hosmer D.W., Lemesow S., Applied Logistic Regression, Wiley, New York, 1989, pp. 82134.

[9] Kim J.W., Park J.H., Park J.W., Doh H.J., Heo G.S., Lee K.J., Quantitative analysis of serum proteins separated by capillary electrophoresis, Clin. Chem. 39 (1993) 689-692.

[10] Kjemtrup A.M., Kocan A.A., Whitworth L., Meinkoth J., Birkenheuer A.J., Cummings J., Boudreaux M.K., Stockham S.L., IrizarryRovira A., Conrad P.A., There are at least three genetically distinct small piroplasms of dogs, Int. J. Parasitol. 30 (2000) 1501-1505.

[11] Kuttler K.L., World-wide impact of babesiosis, in: Ristic M. (Ed.), Babesiosis of domestic animals and man, CRC Press, Boca Raton, FL, 1988, pp. 1-22.

[12] Lobetti R.G., Jacobson L.S., Renal involvement in dogs with babesiosis, J. S. Afr. Vet. Assoc. 72 (2001) 23-28.

[13] Lobetti R.G., Mohr A.J., Dippenaar T., Myburgh E., A preliminary study on the serum protein response in canine babesiosis, J. S. Afr. Vet. Assoc. 71 (2000) 38-42.

[14] Mackinnon B., Sharkerdi L., Deighan C.J., Fox J.G., O’Reilly D.S., Boulton-Jones M., Urinary transferrin, high molecular weight proteinuria and the progression of renal disease, Clin. Nephrol. 59 (2003) 252-258.

[15] Maegraith B., Gilles H.M., Devakul K., Pathological processes in Babesia canis infections, Z. Tropenmed. Parasitol. 8 (1957) 485514.

[16] Nelson D.A., Morris M.W., Basic examination of blood, in: Henry J.B. (Ed.), Clinical Diagnosis and Management by Laboratory Methods, W.B. Saunders, Philadelphia, PA, 1996, pp. 549-593.

[17] Persing D.H., Mathiesen D., Marshall W.F., Telford S.R., Spielman A., Thomford J.W., Conrad P.A., Detection of Babesia microti by 
polymerase chain reaction, J. Clin. Microbiol. 30 (1992) 2097-2103.

[18] Stevenson F.T., Greene S., Kaysen G.A., Serum alpha 2-macroglobulin and alpha 1inhibitor 3 concentrations are increased in hypoalbuminemia by post-transcriptional mechanisms, Kidney Int. 53 (1998) 67-75.

[19] Taboada J., Babesiosis, in: Greene C.E. (Ed.), Infectious diseases of the dog and cat, 2 nd ed., W.B. Saunders, Philadelphia, PA, 1998, pp. 473-481.

[20] Van Heerden J., The transmission of Babesia canis to the wild dog Lycaon pictus (temmick) and blackbacked jackal Canis mesomelas Schreber, J. S. Afr. Vet. Assoc. 51 (1980) 119-120.
[21] Wang H.P., Liu C.M., Separation and identification of human serum proteins with capillary electrophoresis, Clin. Chem. 38 (1992) 963-964.

[22] Wozniak E.J., Barr B.C., Thomford J.W., Yamane I., McDonough S.P., Moore P.F., Naydan D., Robinson T.W., Conrad P.A., Clinical, anatomic and immunopathologic characterization of Babesia gibsoni infection in the domestic dog (Canis familiaris), J. Parasitol. 83 (1997) 692-699.

[23] Zahler M., Rinder H., Schein E., Gothe R., Detection of a new pathogenic Babesia microti-like species in dogs, Vet. Parasitol. 89 (2000) 241-248. 